\title{
THE STARK INACCESSIBILITY OF MEDICAL CARE IN RURAL INDIANA: JUDICIAL AND LEGISLATIVE SOLUTIONS
}

\author{
Thomas F. Martin II
}

PART I

A. Geographic Accessibility: Hospitals.

B. Medically Underserved Areas and Populations in Indiana.

C. Health Professional Shortage Areas....................88 839

PART II

A. Medical Malpractice and Its Effects

$B$. The Conception and History of the Locality Rule.843

C. The Modified Locality Rule Debuts in Indiana Jurisprudence

D. The Modified Locality Rule as a Solution to Inaccessibility

E. Gross Negligence as a Solution to Inaccessibility. 855 PART III 860

A. Existing Accessibility Programs .........................860

B. Critical Access Hospitals...................................864

C. Geographic Accessibility: State-Owned and Operated Critical Access Hospitals and Support for the Establishment of Acute Care and Primary Care Hospitals .......................................................865

D. Medical Personnel Accessibility: The "Pay-to-Drive" and the "Rural Practice Benefits Program"...........872

E. Conclusion.....................................................8 874

J.D. Candidate, 2014, Indiana University Robert H. McKinney School of Law, Indianapolis, Indiana; B.A., May 2010, Indiana University, Bloomington, Indiana. 


\section{INTRODUCTION}

There is a widespread disparity of accessibility to medical care within Indiana. This disparity of access to quality health services in certain areas of Indiana is seemingly nothing less than a full blown crisis. While much recent legislative focus and attention have been devoted to medical insurance coverage, a general lack of accessibility to healthcare, especially in rural areas, has remained unsettled. This article outlines the maldistribution of hospitals and healthcare professionals within Indiana with a focus on a comparative analysis of rural and urban locales, and it also seeks to explore and offer legal solutions to this humanitarian inequity.

In part I of this note, the nature and scope of the inaccessibility to medical facilities and the shortage of medical professionals in rural areas within Indiana are highlighted. In particular, the geographic placement of hospitals throughout the state is analyzed. Additionally, data on the extent of primary care physician availability in rural areas is reviewed.

Moreover, in part II of this note, medical malpractice and the effects thereof are examined in the context of the absence of adequate access to healthcare institutions and the waning number of medical professionals practicing in rural Indiana. Judicial measures may exist to remedy, to a certain extent, the inaccessibility of medical care in rural areas. Principally, two judicial measures will be proposed in part II of this note. These include adoption of the modified locality rule as the standard of care for rural physicians and alternatively the adoption of gross negligence as the threshold of malpractice liability for rural physicians.

Additionally, comprehensive legislative measures are also available to combat the inaccessibility of medical care in rural areas. Primarily, two legislative measures will be of focus in part III of this note. These are the establishment of state-funded and operated hospitals and the establishment of a program which would facilitate the 
redistribution of medical professionals from large cities to rural Indiana.

\section{PART I}

Accessibility of medical care within certain areas of Indiana is shockingly limited. These areas tend to constitute agrarian locales. In order to accurately portray the current state of accessibility to medical treatment within these non-urban locales, two types of medical care accessibility will be assessed in this note. These are geographic and medical personnel accessibility. Geographic accessibility, usually referred to as medically underserved areas or populations, constitutes the availability of medical facilities or services in a certain locale or area. Medical personnel accessibility, herein often referred to as health professional shortage areas, means the adequacy or inadequacy of the amount of certain medical professionals given their ratio to the population of a certain geographic area.

\section{A. Geographic Accessibility: Hospitals}

Hospitals play a vital role throughout the healthcare infrastructure in delivering many types of health services. Hospitals, through their physicians and staff, most notably bear the assumed responsibility of diagnosing a plethora of ailments and diseases, establishing efficient systems for the provision of preventative care, responding to epidemics and other health crises, treating infectious disease, performing complex inpatient and outpatient surgeries, treating severe injuries under extenuating circumstances, and providing means of long term care. These services are indispensable to maintaining the well-being of many Americans, and indirectly the availability of these services helps to maintain a thriving society.

Specifically, proper and robust healthcare delivery intuitively effectuates healthier living. In turn and generally speaking, a healthy population is likely to be more productive than is one that struggles to obtain and maintain 
good health. ${ }^{1}$ This is due to the straightforward notion that people who suffer inadequate health services are corporally less capable of bearing the demands of activity. In other words, sickness of the human body takes an adverse toll on human happiness and productivity, and thus illness takes priority in everyday living. Contrarily, healthy populations are better able to center and focus their energies on endeavors such as education, commerce, philanthropy, and artistic expression, which as a result benefits society as a whole. Hospitals act as the foundation of the healthcare delivery system which is integral to societal health and productivity.

As of 2010, there are sixteen rural counties in Indiana that contain no acute care hospital. ${ }^{2}$ Acute care is defined as medical treatment of a severe and short-lasting injury or disease. ${ }^{3}$ Acute care hospitals generally provide many important medical services consisting of inpatient and outpatient treatments. Most of the counties that lack an acute care facility are found south of Indianapolis or in what may be considered southern Indiana. ${ }^{4}$

Southern Indiana has historically faced greater economic hardship than other regions of the state. ${ }^{5}$ As of 2000, eighteen of Indiana's poorest thirty counties were located in southern Indiana. ${ }^{6}$ Moreover, the real per capita personal income of twenty-seven Indiana counties, fifteen of which are found south of Indianapolis, are at least 25 percent

1 Terrell Zollinger et AL., IND. UNIV. CTR. FOR Health POLICY, CRITICAL ShORTAGE OF PHYSICIANS AND NuRSES PROJECTED FOR INDIANA 4 (Marilyn Yurk ed., 2008), available at http://www.healthpolicy.iupui.edu/ PubsPDFs/Critical\%20Shortage\%20of\%20Physicians\%20and\%20Nurses.pdf.

2 AFFLlLATED SERV. PROVIDERS OF IND., INC., IND. STATE DEP'T OF HeAlth, Indiana State RURAL Health Plan 35 (2011), available at http://www.in.gov/isdh/files/IndianaStateRuralHealthPlan2011final.pdf.

3 MERRIAM-WEBSTER, MEDICAL DICTIONARY (2012), available at http://www.merriam-webster.com/medical/acute\%20care (last visited Nov. 23,2012 ).

4 AfFiliated Serv. Providers of IND., INC., IND. State DeP'T of HEALTH, supra note 2 , at 35 .

5 Scott MacGregor, Much of Indiana Faces More Blight Than Bloom: Metro Area's Economic Upsurge Hasn't Fanned Outward, INDLANAPOLIS STAR, May 15, 2002, at A1.

$6 \quad I d$. 
below the national personal income average. 7 The disproportionate regional distribution of acute care hospitals reflects the disparate distribution of wealth within the state. Based on these facts, it may be that southern Indiana counties are fiscally incapable of establishing public hospitals. Specifically, the poor economic state of these counties most likely severely weakens the taxation pool on which county governments must rely to establish and maintain public institutions. At the same time, it seems that the private sector has refused to invest in the povertystricken counties for want of an economic incentive.

The nonexistence of acute care hospitals within certain Indiana counties has the potential to produce devastating results in the context of individual life and also in the wellbeing of the population of those counties. For example, if an individual finds himself severely injured within a county that is without an acute care provider, say in a car accident on the back-roads of Crawford County ${ }^{8}$, then he must seek treatment in a nearby county. In some accident scenarios, undoubtedly time is of the essence and failure to speedily obtain treatment could result in loss of life or permanent disability.

Even more striking, it would take at least sixty minutes to reach a level 1-3 trauma center in 8.18 percent of the total geography of Indiana. ${ }^{9}$ And while 8.18 percent seems insignificant, and it would be in most non-life threatening instances, it is staggering in the context of a life-threatening injury. However, some might argue that such a small percentage $(8.18 \%)$ of the state, where medical response time is delayed, is confined and affects only a small amount of people. This assertion fails to consider the mobility of the population; in-state and out-of-state travelers, commercial or not, frequently must move across these areas of delayed

7 Morton J. Marcus, The Rich Stay Rich Among Indiana's Counties, IND. BUS. REV., Fall 2000, at 1, available at http://www.ibrc.indiana.edu/ ibr/2000/fall00/01.pdf.

8 Crawford County is located in south central Indiana along the Ohio River.

9 Univ. of Pa., Indiana: Trauma Center Lvl 1-3 Access 2010, TRAUMAMAPS.ORG, http://www.traumamaps.org/Trauma.aspx (last visited Nov. 22, 2012). 
response, which augments the at-risk population. The existence of these delayed response areas is indicative of the need for the construction of new hospitals. Failure to invest in the construction of these hospitals will necessarily result in the continued unreasonable exposure of certain populations, residents and passersby, to a risk of untimely treatment, which could produce negative consequences such as prolonged recovery or sometimes even death.

Hospitals, besides providing general medical care, also offer many specialty services which range from cardiologic to podiatric services. The importance of certain specialties cannot be overstated. Specialists provide an expertise in the diagnosis and treatment of complex ailments and conditions that cannot be matched in general medicine. Obstetrics is one of these expert fields and it is a staple in the maintenance of women's overall health. Specifically, obstetrics is a field of medicine that pertains to pregnancy and childbirth. ${ }^{10}$ Despite its major importance to such a numerous class, there are twelve Indiana counties that have no obstetrical services available. 11 The potential consequence of this dearth of obstetrical services in certain Indiana counties is palpable and appalling. Statistics are incapable of illustrating the disturbing adverse effects of the absence of obstetrical services in these counties. Hypothetically, due to the lack of obstetrical services, a pregnant woman residing in Crawford County for example, who begins labor, would be required to travel to a neighboring county to receive medical assistance. Under these pressing circumstances, it is plausible that the woman could be forced to give birth without assistance, possibly endangering the welfare of both mother and child. Some might rightly posit that the above example is conjecturally anecdotal and maybe even extreme. However, it must be remembered that effective legal systems do not only concern themselves with merely remedying definable and

10 MERRIAM-WEBSTER, MEDICAL DICTIONARY (2012), available at http://www.merriam-webster.com/medical/obstetrics (last visited Nov. 23, 2012).

11 AFFiliated Serv. PROVIDERS OF IND., INC., IND. STATE DEPT OF HEALTH, supra note 2, at 35 . 
empirically proven problems and imperfections. An effective legal system takes into account potential consequences of an imperfect arrangement of variables, and it intuitively and prophylactically implements measures that reduce or eliminate those consequences. Given the current preeminent state of technology and the economic powerhouse status of the United States, it is unthinkable and deplorable that such a set of conditions exists that could lead to a deprivation of medical assistance to such a large class of persons.

\section{B. Medically Underserved Areas and Populations in Indiana}

The Health Resources and Services Administration (HRSA) is an agency within the U.S. Department of Health and Human Services. ${ }^{12}$ The Health Resources and Services Administration is responsible for facilitating greater access to health care for underserved populations and suspect classes. ${ }^{13}$ At the time of writing this note, according to the HRSA, there are fifty-four medically underserved areas in Indiana. ${ }^{14}$ A medically underserved area is one which lacks adequate personal health services given the population. ${ }^{15}$ Medically underserved areas are designated by county, a group of contiguous counties, or in cities by census tracts which are comprised of like economic and demographic characteristics. ${ }^{16}$ Also according to HRSA, there are twenty-

12 U.S. PRINTING OFFICE, THE UNITED STATES GOVERNMENT MANUAL (2012), available at http://www.usgovernmentmanual.gov/ Agency.aspx?EntityId=Ldrc/ujFJeo=\&ParentEId $=+$ klubNxgV0o=\&EType $=j$ Y3M4CTKVHY=.

13 Id.

14 Health Res. \& Servs. Admin., U.S. DeP'T of Health \& Human SERVS., MEDICALLiY UNDERSERVED AREAS/PopUlations (MUA/P): STATE SUMMARY OF DESIGNATED MUA/P 1 (2012), available at http://datawarehouse.hrsa.gov/topics/shortageAreas.aspx.

15 Health Res. \& Servs. Admin., U.S. Dep't of Health \& Human Servs., Shortage Designation: Health Professional Shortage Areas \& Medically Underserved Areas/Populations, BHPR.HRSA.Gov, http://www.hrsa.gov/ shortage/ (last visited Nov. 23, 2012).

16 Health Res. \& Servs. Admin., U.S. Dep't of Health \& Human Servs., Medically Underserved Areas/Populations: Guidelines for MUA and MUP 
four medically underserved populations within Indiana. 17 The distinguishing characteristic between medically underserved areas and populations is that the designation of medically underserved populations is focused more narrowly on a demographic group which is impaired from obtaining primary medical services due to economic, cultural, or linguistic misfortunes. ${ }^{18}$

There are several factors that are applied to determine whether a particular area or population qualifies as medically underserved. These factors include the "ratio of primary care physicians to the population, infant mortality rate, percentage of the population which is age 65 or older, and percentage of the population with family income below the poverty level."19 Based on the severity of these factors, a score is computed for an area. The score for an area is then measured against the national median score, which lies on a scale of 1-100. A score of zero is the lowest possible medically underserved score, and 100 is the highest and best medically served score. If the overall score for a particular area falls below the national median score of sixty-two, then the area is considered medically underserved. ${ }^{20}$

Despite the failure of certain areas to qualify for the designation of medical underservice, the Governor may request that those areas receive the designation due to exceptional circumstances. 21 According to the HRSA, nineteen areas or populations have received this special type of governor designation. ${ }^{22}$ In all, a combination of

Designation, BHPR.HRSA.GOV, http://www.hrsa.gov/shortage/ mua/index.html (last updated June, 1995).

17 Health Res. \& SeRvs. Admin., U.S. Dep'T of Health \& HumaN SERVS., supra note 14 .

18 Health Res. \& Servs. Admin., U.S. Dep't of Health \& Human Servs., supra note 15.

19 Medically Underserved Areas and Population Groups, 41 Fed. Reg. 45718 (Oct. 15, 1976) (codified at 42 C.F.R. $\$ 51 C .102(e)(1-4)(2013)$ ).

20 Health Res. \& Servs. Admin., U.S. Dep't of Health \& Human Servs., supra note 16.

21 Id.

22 Health Res. \& SeRvs. AdMIN., U.S. DeP'T OF Health \& Human SERVS., STATE PROFLE: INDIANA: STATE IN HHS REGION V 8(2012), available at http://datawarehouse.hrsa.gov/HGDWReports/RT_App.aspx?rpt=SP . 
ninety-seven medically underserved areas and populations exist in Indiana. ${ }^{23}$ Overall, rural areas and inner cities are more likely to suffer from medical underservice. ${ }^{24}$

\section{Health Professional Shortage Areas}

Many areas and population groups in Indiana particularly suffer a shortage of primary care health professionals. The HRSA is also required to designate areas where there is a shortage of health professionals. The health professional shortage area (HPSA) classification contains three fields or services of health care. These are primary care, dental care, and mental health care. ${ }^{25}$ Additionally, within the primary care HPSA label, there are three distinct subcategory designations which include geographic area (which has a shortage of health professionals), population group, and facility. ${ }^{26}$ For each of these subcategories of the HPSA designation, there are established criteria which must be satisfied in order that the HPSA designation attach. ${ }^{27}$ For example, in order for a geographic area to qualify for designation as a primary care health professional shortage area, the geographic area must: be an area where it is logical to provide primary care services, show that the ratio of the area's population to full time primary care physicians is not lower than 3,500 to 1 or not less than 3,000 to 1 if the area displays a uniquely high demand for primary care physicians or an "insufficient capacity of existing primary care providers," and show that primary care physicians in surrounding areas are overworked, far removed, or unable to be reached by the

23 Id.

24 ZOLLINGER ET AL., supra note 1.

25 Health Res. \& Servs. Admin., U.S. Dep't of Health and Human Servs., Shortage Designation: Health Professional Shortage Areas (HPSAs): Designation Criteria and Guidelines, BHPR.HRSA.Gov, http://bhpr.hrsa.gov/ shortage/hpsas/designationcriteria/index.html (last visited Nov. 23, 2012).

26 Health Res. \& Servs. Admin., U.S. Dep't of Health and Human Servs., Shortage Designation: Primary Medical Care HPSA Designation Overview, BHPR.HRSA.GOV, http://bhpr.hrsa.gov/shortage/hpsas/designation criteria/primarycarehpsaoverview.html (last visited Nov. 23, 2012).

27 Id. 
population of the area. ${ }^{28}$ For each criteria listed above, there are guidelines which are determinative of whether the geographic area meets the relevant criterion. For example, one guideline for determining whether a geographic area, which has a population to primary care physicians ratio of more than 3,000 to 1 but less than 3,500 to 1 , displays a uniquely high demand for primary care physicians, is that the area suffers an infant death rate of more than 20 per 1,000 births. ${ }^{29}$

As of 2012, Indiana has received 104 total designations of primary care health professional shortage areas. ${ }^{30}$ Indiana fairs better than four out of five states listed in its region in regard to the total amount of primary care designations. ${ }^{31}$ However, Indiana falls behind only Illinois in having the greatest number of counties to receive the primary care HPSA designation within its region. ${ }^{32}$ As of November 27th, 2012, 1,107, 243 Hoosiers live in or are a part of an area, population, or facility which suffers a shortage of primary care health professionals. ${ }^{33}$ In Indiana's region and as of November 27th, 2012, only Ohio, Illinois, and Michigan have more residents who are living in or are a part of an area, population, or facility which suffers a shortage of primary care health professionals. ${ }^{34}$

On average, there are 53.6 primary care physicians per 100,000 Hoosiers. ${ }^{35}$ The national average amounts to 90.5

28 Id: Criteria for Designation of Areas Having Shortages of Primary Medical Care Professional(s), 42 C.F.R. Pt. 5, App. A. (2012).

$29 \quad 42$ C.F.R. Pt. 5, App. A. Part I(B)(4)(b).

30 Health Res. \& SERVS. ADMIN., U.S. DeP'T OF Health \& HuMAN SERVS., supra note 22 , at 9.

31 BUREAU OF CLINICIAN RECRUTTMENT \& SERV., U.S. DEP'T OF HEALTH \& Human Servs., Designated Health Professional Shortage AREas (HPSA) STATISTICS: PRIMARY CARE 2 (2012). There are five other states in Indiana's region. Id.

$32 \quad I d$.

$33 \quad I d$.

34 Id.

35 HaNNAH MaXeY ET AL., IND. UNIV. CTR. FOR HEALTH POLICY, INDIANA PRIMARY HEALTH CARE: DESCRIPTION, DISTRIBUTION, CHALLENGES, \& STRATEGIC RECOMMENDATION TO EMPOWERED DECISION MAKING 6 (2012), available at http://www.ic4n.org/wp-content/uploads/2013/03/IndianaPrimary-Health-Care.pdf. 
primary care physicians per 100,000 . Indiana's ratio of primary care physicians per 100,000 is 40 percent below the national average. ${ }^{36}$ Non-metropolitan Indiana counties suffer more acutely from this shortage of primary care physicians as they generally have less primary care physicians per the population than metropolitan counties have. ${ }^{37}$ Specifically, 98 percent of rural counties in Indiana are deficient in primary care specialists, and thus they do not satisfy the U.S. standard ratio of primary care specialists per $100,000 .{ }^{38}$ In order to adequately fulfill demand for medical services throughout the state, 5,000 more physicians need to be injected into the workforce. ${ }^{39}$ In sum, Indiana falls behind thirty-four states in the accessibility of physicians who provide primary care. 40

\section{PART II}

\section{A. Medical Malpractice and Its Effects}

Medical errors and the litigation that flows from them have burdened the healthcare industry in the past. ${ }^{41}$ The severe and increasing costs of malpractice litigation continue today to plague the healthcare industry. ${ }^{42}$ Also, medical professionals' perception of a litigious consumer base and legal favoritism to these consumers' cause is remarkably apparent. ${ }^{43}$ In the context of rural practice then, the question becomes whether the variables and unique set of conditions of rural practice influence and

\footnotetext{
$36 \quad I d$.

37 ZOLLINGER ET AL., supra note 1, at 7.

$38 \quad I d$. at 1.

$39 \quad$ Id.
}

40 AFFlliated Serv. Providers of IND., InC., IND. State DeP'T of HEALTH, supra note 2, at 8.

41 Alec Shelby Bayer, Looking Beyond the Easy Fix and Delving into the Roots of the Real Medical Malpractice Crisis, 5 HOUS. J. HEALTH L. \& POL'Y 111, 115-16 (2005).

42 Id. at 114-15.

43 See id. at 116; Alan G. Williams, The Cure for What Ails: $A$ Realistic Remedy for the Medical Malpractice "Crisis", 23 STAN. L. \& POL'Y REV. 477, 487 (2012). 
exacerbate medical professionals' perception and fear of malpractice litigation, resulting in a greater disincentive to practice there. ${ }^{44}$

In 2002, one-third of U.S. hospitals experienced a 100 percent increase in medical liability insurance premiums. ${ }^{45}$ It is also reported that in response to rising liability premiums, 25 percent of U.S. hospitals have reduced the extent to which they provide or have altogether terminated certain medical services. ${ }^{46}$ The rising costs of malpractice litigation have also negatively affected the ability of some all-important trauma centers to feasibly remain in operation. ${ }^{47}$ Additionally due to rising premiums, in some states physicians have closed their doors and moved in search of a more legally favorable place to practice. ${ }^{48}$ Moreover, some physicians have summarily ended their careers in medicine due to the high costs of malpractice litigation. 49

In 2011, 167 medical malpractice claims resulted in payment in Indiana. ${ }^{50}$ These payments amounted to $\$ 22$, $473,800.51$ The payments however do not reflect the total costs of malpractice litigation. Defendant physicians or their insurers must also bear the costs of attorney's and expert witness' fees and other transactional costs in preparing for litigation and in defending against malpractice claims. Even defendant physicians who are not found to be liable still incur some litigation costs. Insurance companies in turn spread these costs across the profession sometimes resulting in higher premiums. As a consequence

44 See Williams, supra note 43 , at 490.

45 Addressing the New Health Care Crisis: Reforming the Medical Litigation System to Improve the Quality of Health Care Hearing Before the S. Subcomm. On Labor, Health and Human Serv. and Educ. of the $S$. Appropriations Comm., 108th Cong. (2003) (statement of Claude A. Allen, Deputy Sec'y of the Dep't of Health and Human Servs.).

46 Id.

47 Id.

$48 I d$.

49 Id.

50 KAISER FAMILY FOUND., STATE HEALTH FACTS: INDIANA: NUMBER OF PAID MEDICAL MALPRACTICE ClaIMS (2011).

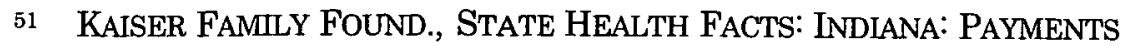
ON MEDICAL MALPRACTICE ClaIms (2011). 
of rising premiums, hospitals and physicians raise the price of their services, and ultimately patients or their medical insurers bear the extra costs of far removed malpractice litigation.

The Indiana Legislature enacted the Medical Malpractice Act to combat the increasing cost of malpractice litigation on the medical field. ${ }^{52}$ The Malpractice Act created a process whereby malpractice claims are submitted to a board of three medical practitioners and a single practicing attorney who oversees the board's legal analysis of each malpractice claim. ${ }^{53}$ The board of physicians makes a legal determination on each claim of whether the physician in question breached the standard of care. ${ }^{54}$ The board's finding in favor of the physician becomes a de facto summary judgment motion in subsequent litigation. ${ }^{55}$ Additionally, although Indiana is a comparative fault jurisdiction, contributory negligence on the part of the patient is a complete bar to recovery in malpractice litigation. ${ }^{56}$

\section{B. The Conception and History of the Locality Rule}

The locality rule in the United States owes its existence to the Kansas Supreme Court, which purportedly first adopted the rule in $1870 .{ }^{57}$ In the late nineteenth century and before the landmark case of Tefft $v$. Wilcox, physicians and surgeons in Kansas were required to exercise that level of ordinary care and skill and to possess that level of knowledge which experts in the field of medicine had

52 Bruce D. Jones, Unfair and Harsh Results of Contributory Negligence Lives in Indiana: The Indiana Medical Malpractice System and the Indiana Comparative Fault Act, 6 IND. HEALTH L. REV. 107, 109-12 (2009).

53 IND. CODE $\S \S 34-18-8-4,34-18-10-1,3,19$ (2012).

$54 \S 34-18-8-4$.

55 Snyder v. Cobb, 638 N.E.2d 442, 447 (Ind. Ct. App. 1994).

$56 \quad$ IND. CODE $\S 34-51-2-1(\mathrm{~b})(1)(2012)$.

57 Brent R. Cohen, The Locality Rule in Colorado: Updating the Standard of Care, 51 U. COLO. L. REv. 587, 588 (1980) (exploring the history of the locality rule). 
espoused and which the profession commonly accepted. 58 Tort law at that time thus pronounced the expectation that the skill and expertise of physicians practicing in smaller towns should be of the same quality and nature as the skill and expertise of physicians working in cities. ${ }^{59}$ Liability then could be established merely by a showing that a defendant physician's conduct deviated from the commonly accepted mode of treatment, with no attention or analysis being paid to the circumstances and conditions of a particular locale. 60

In Tefft, plaintiff Wilcox brought suit alleging that the defendant physician's treatment of his arm caused him to lose the use of it and his shoulder. ${ }^{61}$ Principally, the Kansas Supreme Court focused their inquiry on evidentiary and jury instruction error. ${ }^{62}$ However, the court clarified the standard of care for physicians practicing in Kansas.

In examining circumstances that may affect a physician's ability to comport his skill and knowledge to the established standards of the profession, the Kansas Supreme Court noted that locality of practice constituted an extenuating circumstance of potential permissible deviation. ${ }^{63}$ The court explained that physicians practicing in larger cities usually possessed greater knowledge and skill in medicine, were endowed with better medical facilities, and had more exposure to routine operations and varying maladies. ${ }^{64}$ The court reasoned that, due to the fact that physicians practicing in small towns had less access to comprehensive facilities and less experience treating diseases, physicians in smaller towns or in rural areas should be held to a lower standard of care and skill than those physicians operating in cities were held. 65 Presumably then, locality with its attendant unique

58 See Tefft v. Wilcox, 6 Kan. 46, 62 (1870) (quoting Elwell on Malpractice).

59 See id.

60 See id.

61 Id. at 54 (quoting Elwell on Malpractice).

62 Id. at 60 (quoting Elwell on Malpractice).

63 Id. at 63 (quoting Elwell on Malpractice).

64 Id. at 63-64 (quoting Elwell on Malpractice).

65 Id. (quoting Elwell on Malpractice). 
conditions would from then onward be instrumental in defining the contours of a physician's standard of care.

\section{The Modified Locality Rule Debuts in Indiana Jurisprudence}

In 1877, the Indiana Supreme Court in Gramm $v$. Boener held that the trial court did not err in refusing to include an instruction to the jury that emphasized strict locality as the applicable standard of care for physician liability. ${ }^{6}$ Plaintiff Boener brought suit alleging that the defendant physician Gramm improperly and ineffectively realigned his broken arm and leg which caused a loss of the use of his arm and a deformity in his leg. ${ }^{67}$ Upon review of the jury instruction, the court ruled that the doctrine of strict locality, which required physicians to only exercise that level of ordinary care and skill that was established in their particular community, was not the applicable law in the state. ${ }^{68}$

The Gramm court reasoned that it was an unthinkable proposition to allow a handful of physicians in a rural community to dictate the standard of care to which they would be held, because quite poignantly some physicians might be incompetent and others could be phonies of the profession. ${ }^{69}$ Quite obviously then, the Gramm court's motivation for uprooting the strict locality rule was founded upon the possibility that pockets of the profession could essentially and unfairly shield themselves from liability. The new rule then would seek to pierce the so-called shield of malpractice protection. The Gramm court ultimately laid down what is known as the modified locality rule. ${ }^{70}$ This new version of the doctrine of locality required physicians to

66 Gramm v. Boener, 56 Ind. 497, 500-01 (1877).

67 Id. at 497.

68 Id. at 500.

69 Id. at 501 ("There might be but few practising in the given locality, all of whom might be quacks, ignorant pretenders to knowledge not possessed by them, and it would not do to say, that, because one possessed and exercised as much skill as the others, he could not be chargeable with the want of reasonable skill.").

$70 I d$. 
exercise that level of care and skill that ordinarily careful and skillful physicians of similar localities exercised. ${ }^{71}$ This slight modification of the locality rule meant that physicians facing malpractice liability could no longer only show, and hence rely on the fact, that their professional conduct comported with the normative conduct of their colleagues practicing in the same town. Hence, the modified locality rule seemingly expanded the scope of inquiry into the established standard of care from a single town perspective to a collective perspective of many towns similarly comprised and situated.

One hundred years later, in Wilson v. Sligar, the Indiana Court of Appeals held that the trial court erred in refusing to allow the plaintiff Wilson to establish, through expert witness testimony, the national minimum standard of care for orthopedic surgeons because such testimony was permissibly intended to illustrate the nature and wide scope of locality applicable to the facts therein. ${ }^{72}$ Plaintiff Wilson sought treatment for a discomfort in her hip, which a surgeon had already operated on in recourse to an injury sustained in a car accident, from defendant Sligar who was an orthopedic surgeon. ${ }^{73}$ Doctor Sligar performed noninvasive methods of remediation, but those efforts failed to alleviate Wilson's suffering. ${ }^{74}$ After further examination of Wilson, Doctor Sligar informed her that a total hip replacement would be necessary. 75 However after consummation of the surgery, plaintiff Wilson developed a neurological condition called foot drop. ${ }^{76}$ Subsequently, Doctor Sligar applied remedial measures to improve the condition, and he counseled that additional surgery was required. ${ }^{77}$ Plaintiff Wilson however rejected the prospect of Dr. Sligar performing the surgery. ${ }^{78}$ Wilson's surgery to

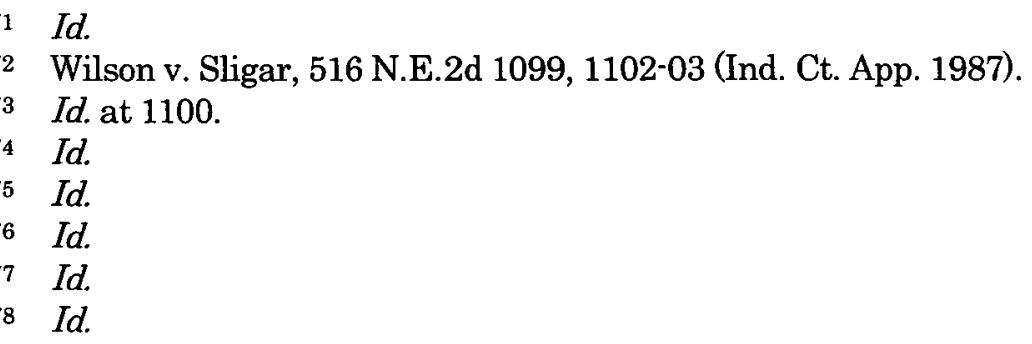


correct the foot drop was performed by two other surgeons. ${ }^{79}$ While performing the surgery, the surgeons noticed some damage to the sciatic nerve and the surgeons came to the conclusion that the damage was a consequence of a retractor applied during Doctor Sligar's hip replacement surgery. ${ }^{80}$ The plaintiff brought suit alleging negligence on the part of Doctor Sligar in the performance of the hip surgery. ${ }^{81}$

In ruling on the trial court's refusal to admit evidence establishing the national minimum standard of care for orthopedic surgeons, the Sligar court explained that the strict locality rule was premised upon avoiding the unfairness of attaching malpractice liability to rural physicians for conditions outside of their control; the court noted that these historic conditions constituted the difficulties of travel and urban physicians' greater access to education, better medical facilities, and skills training through practice. ${ }^{82}$ The court noted that advancements in mobility, increased access to education, equal quality of medical facilities and equipment, and better avenues of acquiring knowledge had seriously weakened the need and usefulness of the strict locality rule. ${ }^{83}$ Ultimately, the Sligar court ruled that the plaintiff's questioning of expert witnesses to establish a national minimum standard of care was permissible because the plaintiff sought to lay a requisite foundation for the testimony. ${ }^{84}$ However, the court ruled that the plaintiff failed to show that the trial court's refusal to admit the testimony amounted to reversible error. ${ }^{85}$

The Sligar court's holding is illustrative of a judicial recognition at the time that national minimum standards of care existed and that these minimum standards were relevant in establishing the scope of locality. Specifically,

$\begin{array}{ll}79 & I d . \\ 80 & I d . \\ 81 & I d . \\ 82 & I d . \text { at } 1101 . \\ 83 & I d . \\ 84 & I d . \text { at } 1102 . \\ 85 & I d . \text { at } 1103 .\end{array}$


this recognition implied that the standard of care established in similar localities did not in fact control in exclusively setting the threshold of liability. Contrarily, the Sligar court's holding stood for the proposition that national minimum standards of care could, in certain cases, trump any pertinent standard established in similar locales. Therefore with the expansion of locality, a defendant physician could no longer solely rely on the fact that her performance was in line with established standards of care in similar locales to avoid liability if it could be shown that national minimum standards existed and the physician's performance failed to meet these standards.

Just five years after Sligar, the Indiana Supreme Court altogether abandoned the modified locality rule in Vergara v. Doan. ${ }^{86}$ Plaintiff Vergaras' son allegedly was injured by the defendant physician's negligent performance of their son's delivery. ${ }^{87}$ The plaintiffs sought appeal after a jury returned a verdict in favor of Dr. Doan, and the Court of Appeals affirmed. 88 On appeal to the Indiana Supreme Court, the plaintiffs argued that the modified locality rule should be abandoned in Indiana. ${ }^{89}$ The Court agreed with plaintiffs and ruled that, "a physician must exercise that degree of care, skill, and proficiency exercised by reasonably careful, skillful, and prudent practitioners in the same class to which he belongs, acting under the same or similar circumstances." 90

The Vergara court echoed the Court of Appeals in Sliger on the reasons for the modern day irrelevance of the locality rule. The court observed that advancements in mobility, communications, and increased access to medical education served to vitiate the foundation for applying the locality rule. ${ }^{91}$ The court however did not completely eradicate locality from the standard of care for physicians. The court

86 Vergara v. Doan, 593 N.E.2d 185, 187 (Ind. 1992) (adopting a national standard of care for physicians).

87 Id. at 186.

88 Id.

89 Id. at 187 (plaintiffs argued that the justifications for the modified locality rule were hollow in the current age).

90 Id.

91 Id. 
explained that locality would no longer be determinative in setting the parameters of the standard of care for physicians. 92 Instead, locality would be a factor among others in determining whether the physician complied with the standard of care. ${ }^{93}$ In ruling on the reversibility of error, the court held that the lower court's instruction to the jury which emphasized the standard of care of a similar community was harmless error, because an additional instruction informed the jury that the defendant's performance could be held to a national minimum standard of care for his specialty if the evidence sufficiently established such standard. ${ }^{94}$

The Vergara decision represents a legal evolution and response to a culmination of a century long progression in technology and medicine. It is unquestionable that the past century has been marked by riveting breakthroughs in medicine, and it is equally apparent that advancements in communication and travel have helped to widely diffuse these developments to a significant percentage of the population. However, the Vergara decision presupposes that this progression has led to equality in the platforms for and nature of delivering medical services. Specifically, the Court overlooked conditions of rural locales such as high patient-to-doctor ratios, overworked physicians, and subpar medical facilities and equipment.

\section{The Modified Locality Rule as a Solution to Inaccessibility}

There is much valid criticism of the locality and the modified locality rule. Critics of the rule argue that unlike today, there was much variation in the standards taught at medical schools in the nineteenth century. ${ }^{95}$ They also point out that metropolitan physicians in the nineteenth century,

$\begin{array}{ll}92 & I d . \\ 93 & I d . \\ 94 & I d . \text { at } 188 .\end{array}$

95 See Samuel J. Stoia, Vergara v. Doan: Modern Medical Technology Consumes the Locality Rule, 2 J. PHARMACY \& L. 107, 108-09 (1993). 
unlike their rural counterparts at that time, had routine and better access to varying diseases and ailments of which they could gain greater knowledge and expertise through practice and treatment. ${ }^{96}$ Also, critics rightly posit that impairments of the diffusion of medical knowledge, such as inefficient means of travel and lack of viable forms of communication, do not exist today as they did in the nineteenth century. ${ }^{97}$ Additionally, those critics suggest that advancements in communications allow rural physicians today to remain up to date in their knowledge of ailments and treatments. ${ }^{98}$ However, there might be persisting conditions today, which the critics of the rule underestimate, that give life to the rule. ${ }^{99}$

Fairness still lies at the heart of the justification for application of the modified locality rule, as it did over one hundred years ago. Nineteenth century courts recognized that conditions outside the control of physicians in a particular area profoundly affected the quality of performance in the delivery of medical care, and those courts in response rightly crafted a lenient rule with a focus on mitigating the harshness of liability in the absence of true fault while providing recourse for those defendants injured due to inexcusable fault. It is true today that some conditions of the nineteenth century, which were cited by courts to highlight the unfairness of an inflexible rule of malpractice liability, have improved. Despite the fact that some reasons for the modified locality rule have waned, it does not follow that a fairness inquiry is completely undermined or inappropriate. Fairness still today remains a viable concern in analyzing the national standard of care rule and its application because of its historical role in

96 Compare Wilson v. Sligar, 516 N.E.2d 1099, 1101 (Ind. Ct. App. 1987), with Tefft v. Wilcox, 6 Kan. 46, 63-64 (1870) (quoting Elwell on Malpractice).

97 See Scott A. Behrens, Call in Houdini: The Time Has Come To Be Released from the Geographic Straitjacket Known as the Locality Rule, 56 DRAKE L. REV. 753, 762 (2008);Cohen, supra note 57, at 595.

98 Behrens, supra note 97, at 763.

99 Henry C. Karlson \& Roger D. Erwin, Medical Malpractice: Informed Consent to the Locality Rule, 12 IND. L. REv. 653, 665-66 (1979) (quoting William Kane, Rural Health Care, 240 J. AM. MED. Ass'N. 2647 (1978)). 
shaping the particular rule at hand and also due to its foundational character in the Anglo-American legal system. Under this legal framework then, applying the national standard of care to rural physicians might be unfair due to the potential existence of conditions outside the control of rural physicians. ${ }^{100}$ Specifically, holding rural physicians to the same standard of care as metropolitan physicians is inequitable if metropolitan physicians have access to better medical facilities. ${ }^{101}$ Also, applying the national standard of care to rural physicians is inequitable if physicians practicing in larger cities have better access to more effective and safer medical technologies.

Applying the national standard of care to rural physicians is unfair if rural physicians work longer hours or service more patients per physician than metropolitan physicians do. In fact, rural physicians on average work more hours and service more patients than metropolitan physicians do. ${ }^{102}$ It could be then that the amount of time that a rural physician allocates per patient is more limited and shorter than the amount of time that a metropolitan physician allocates per patient due to the greater number of patients that a rural physician services. If this is true, then rural physicians are most likely exposed to a greater risk of misdiagnosis or inadequate treatment due to having less time to commit per patient. For example, a rural physician may find it necessary to speed the process of a particular patient visit in order to perform check-ups and treat as many rural patients as he is expected. This could result in the rural physician failing to notice a symptom of an underlying disease whereas a metropolitan physician would discover the symptom due to having more time to commit to the particular patient. Consequentially, the patient then might bring suit against the rural physician under a theory

100 See id. at 663, 665-66.

101 See id. at 666 (arguing that it would be unfair to hold rural physicians to a higher standard of care if differences in the standard of care between rural and non-rural communities exist).

102 David A. Matsa, Does Malpractice Liability Keep the Doctor Away? Evidence from Tort Reform Damage Caps, 36 J. LEGAL STUD. S143, S168 (2007). 
of negligent inspection and failure to diagnose. If the national standard of care is applied in lieu of the modified locality rule in this instance, then it is almost certain that the plaintiff would seek to show that the rural physician's shorter duration of inspection of the plaintiff breached the customary standard of time for inspection as established by physicians practicing in city hospitals. Holding rural physicians to this metropolitan standard would be unfair because the shortage of health professionals in rural areas virtually requires rural physicians to see more patients and consequentially stretches the physicians' performance capacity. Moreover, in order to comply with this urban standard, rural physicians would most likely receive fewer patients per day, and in turn this would worsen the state of inaccessibility of medical care in rural areas.

However, even if rural physicians are able to spend on average the same amount of time per patient as metropolitan physicians spend, it still remains that rural physicians work more hours per week than metropolitan physicians. Working longer hours while treating more patients might place a heavier strain on rural physicians that could result in more professional mistakes being made. This should not imply that stress and strain due to over exertion are per se justifications for denying recovery in a malpractice action. However, the establishment of the standard of care in this instance based on the work place customs of metropolitan physicians could set the expectation of conduct at an unattainable level for rural physicians. In other words, the unique circumstances of rural practice may, to an extent, undermine or even thwart compliance with a standard based on urban custom. Adjusting to this metropolitan standard could require rural physicians to work less hours thereby resulting in a decrease in the number of patients treated. As a matter of public policy, this is untenable due to the existing medical underservice of rural areas in Indiana.

Although Indiana has enacted pro-physician medical malpractice legislation, the modified locality rule would particularly provide an incentive for physicians to practice in rural areas. Physicians, in deliberating about where to 
establish a practice, most likely base their decision on rational considerations. Arguably, their decision to practice in a city, in the suburbs, or in the country is largely reached through a cost-benefit analysis. Some of these direct costbenefit factors are the amount of compensation, the amount of work hours, the nature and extent of opportunities for professional growth, the nature of the local market, and the nature of legal regimes. Comprehensive risk assessment then is invaluable to their ultimate decision. In reaching this professional decision, the fact that the law will impose upon a physician practicing in a rural area the performance expectations of metropolitan physicians, who might have access to better medical facilities, expensive and advanced medical technologies, and more time to devote to each patient, will be a disincentive for the physician to choose to engage in rural practice.

The application of the modified locality rule might allow rural physicians to sometimes escape malpractice liability, where under the national standard of care they would otherwise be held liable, and this safety net could potentially curb the cost of maintaining a viable rural practice. Therefore, the lowered costs of practicing in a rural area might entice physicians to begin or continue practicing there.

Research suggests that statutory caps on non-economic damages in malpractice suits have increased physician supply in rural areas. An analysis of the effects of damage caps by Matsa shows that caps do not increase physician supply on a statewide level, but they increase physician supply in the "most rural areas" by 3-5 percent. ${ }^{103}$ Moreover, Matsa concludes that caps on damages particularly increase the supply of surgical specialists and supporting specialists in the "most rural areas." 104 His report indicates that the caps increase surgical specialists by 10 percent and supporting specialists by 12 percent in "most rural areas," respectively. ${ }^{105}$

103 Id. at S162.
104 Id. at S165.
105 Id. 
Application of the modified locality rule has the potential to effectuate an even greater increase in the supply of rural physicians. The modified locality rule, unlike damage caps, affects the determination of liability. In essence then, the modified locality rule with its narrower reach of liability may decrease the amount of successful claims of malpractice. A statutory cap on damages however is not determinative in a finding of liability and does not limit the amount of successful malpractice claims. Thus, the application of the modified locality rule would altogether eliminate litigation costs (e.g. a judgment) in a given case, whereas liability would not be avoided in the context of a cap on damages and a consequential award for the defendant would only be decreased to the extent of noneconomic damages. If damage caps increase physician supply in rural areas by lowering malpractice litigation costs, then it follows that another legal remedy which entirely eliminates litigation costs could be just as and possibly even more effective in creating a higher supply of rural physicians. However this assertion presumes that the application of modified locality rule would be just as reliable in reducing malpractice costs as a mandated cap on damages. Notwithstanding this assumption, the modified locality rule should be considered in the adoption of judicial solutions to combat the inaccessibility of medical care due to its potential to create fairness in malpractice litigation and to make rural practice an attractive and enjoyable endeavor.

However, if the critics of the modified locality rule are correct in their argument that the need for the modified locality rule has completely disappeared, then other judicial means of combating the inaccessibility of medical care in rural areas are necessary. The application of gross negligence as the standard of medical malpractice liability for rural physicians may serve as a potential remedy for the inaccessibility to medical care. 


\section{E. Gross Negligence as a Solution to Inaccessibility}

An alternative to implementing and applying the modified locality rule to physicians practicing in rural areas is the adoption of gross negligence as the threshold of medical malpractice liability for rural physicians. Adoption of the gross negligence standard might act as an incentive for physicians to practice in rural areas due to its potential effect of decreasing the cost of malpractice liability. The implementation of gross negligence rests almost solely on a utilitarian justification, whereas implementation of the modified locality rule is premised largely on fairness with an underlying objective of creating community benefit. The application of gross negligence would directly benefit physicians by providing a degree of immunity while simultaneously it would thwart the interest of an injured patient to receive compensation. However in utilitarian terms, a rural community would benefit overall even at a single patient's loss of compensation because a degree of physician immunity would incentivize rural practice thereby increasing the supply of physicians and creating greater access to healthcare in the community.

The adoption of gross negligence has the potential to attract physicians to rural areas. As mentioned above, the costs of malpractice litigation have been staggering and detrimental to the medical field. ${ }^{106}$ Lowering the cost of malpractice liability by adopting gross negligence as the threshold of liability for rural physicians may have the effect of incentivizing rural medical practice.

While the application of a gross negligence standard to the liability of rural physicians may be deemed grossly unfair to patients and even a radical approach, the goal of eradicating the severe inaccessibility of medical care in rural areas is essential, and it most likely outweighs the temporary costs to quality and consequentially the costs to

106 See Daniel Eisenberg \& Maggie Sieger-Joliet, The Doctor Won't See You Now, TTME, Jun. 09, 2003, at 46, available at http://www.time.com/ time/magazine/article/0,9171,1004970-1,00.html (noting, however, that premiums are more affordable in Indiana than they are in other highpremium states); Williams, supra note 43 , at $480-85$. 
some unfortunate patients. Several societal benefits will materialize due to greater accessibility of medical care. Inefficiencies in providing and gaining access to care will most likely be minimized. Specifically, transaction costs of patients and physicians such as time and money spent traveling and seeking out medical resources, medical errors in referencing between doctors, 107 and higher and inflated malpractice premiums will be reduced. Also, application of a gross negligence standard would promote redistribution of medical resources to the locales where they are most needed. Instead of allocating resources to areas where they will be over consumed, medical resources will be directed to areas and populations where their true market value can be best exploited. Also, with increased access to healthcare in rural areas, the overall health of citizens may improve. With an improvement in overall health, productivity in many areas may be bolstered. In sum and as aforementioned, a healthier population will be able to spend more of its resources on commerce, education, and leisure activities that will greatly benefit society in the long run.

The Indiana Legislature has recognized the need to provide physicians in certain circumstances a degree of civil immunity in order to reap overarching societal benefits. One such high-stakes circumstance in which Indiana affords great protection to physicians is when they volunteer their expertise and service to clinics and health facilities that do not require payment for medical services. ${ }^{108}$ Under this circumstance, malpractice liability cannot attach unless the physician's conduct rises to gross negligence. ${ }^{109}$ Civil immunity in this instance is founded upon the public purpose of facilitating greater access to healthcare for the uninsured and other suspect classes, and this purpose overrides the interest of the injured patient to be economically restored. Additionally, it seems that the

107 This would most likely be true if physicians of general medicine were able to refer patients to specialists whom they work alongside. This could potentially reduce errors in communicating the medical history and nature of the disease and treatment of patients.

108 IND. CODE $\S 34-30-13-1$ (2012).

109 Id. $\S \S 34-30-13-1,2$. 
intent of the Legislature is two-fold in heightening protection against liability in this circumstance. Firstly, the statute intends to reward physicians for acting on behalf of societal interests. In other words, the statute implies that it would be unfair to expose physicians to a liability based on ordinary negligence due to the fact that the physicians' actions are not performed for the sake of self-interest. More importantly however, the statute intends to promote the continuance of philanthropy in healthcare in order to fulfill the public purpose of expanding access to healthcare.

Indiana courts should be mindful of public purpose and policy and societal interests in fashioning the particulars of a standard of gross negligence. A standard of gross negligence should be formidable in creating greater access to healthcare for rural citizens. At the same time, the standard must contain checks against potential abuses that would undermine its purpose. A standard of gross negligence that leans too far in favor of physician protection would ignore the public's interest in receiving quality healthcare. A standard that provides too little physician protection against liability would make the effectiveness of the standard hollow. Against this backdrop of balancing public purpose and policy with other societal interests, Indiana courts should promulgate a workable definition and standard of gross negligence to be applied in cases of rural malpractice. Northern Indiana Public Service Company v. Sharp illustrates the current definition of gross negligence in Indiana.

In Sharp, the plaintiff brought suit under a theory of gross negligence in accordance with the Indiana Civil Defense and Disaster Law of 1975.110 On appeal, the Indiana Supreme Court reviewed the court of appeals' decision that the defendant electric company did not owe a duty to a truck driver who was electrocuted by a cable that the electric company operated. ${ }^{111}$ The Indiana Supreme Court defined gross negligence as, "[a] conscious, voluntary act or omission in reckless disregard of . . . the

110 Northern Ind. Pub. Serv. Co. v. Sharp, 790 N.E.2d 462, 464 (Ind. 2003).

111 Id. at 464-65. 
consequences to another party." 112 In further defining gross negligence, the issue precisely becomes what constitutes "reckless disregard."

The Restatement (Second) of Torts explains that, "In the construction of statutes which specifically refer to gross negligence, that phrase is sometimes construed as equivalent to reckless disregard." 113 Further, the Restatement defines recklessness as follows,

\begin{abstract}
The actor's conduct is in reckless disregard of the safety of another if he does an act or intentionally fails to do an act which it is his duty to the other to do, knowing or having reason to know of facts which would lead a reasonable man to realize, not only that his conduct creates an unreasonable risk of physical harm to another, but also that such risk is substantially greater than that which is necessary to make his conduct negligent. ${ }^{114}$
\end{abstract}

In formulating a legal definition and standard of gross negligence, it is imperative to include measures that will uphold society's interests in the reliability and integrity of the healthcare system. Particularly, quality should not be so degraded as to make widened accessibility fruitless and meaningless. A recklessness standard of malpractice, as defined by the Restatement, for rural physicians is untenable because such a standard would destroy the quality of care provided by rural physicians. This recklessness standard would permit a rural physician's conduct to greatly surpass the conventional negligence threshold without incurring liability unless the risk created by the rural physician's conduct was substantially greater than a risk created by merely negligent conduct.

Due to the potentially severe adverse effects of the Restatement's recklessness standard on the quality of medical care, Indiana courts should adopt a definition of

112 Id. at 465.

113 RESTATEMENT (SECOND) OF TORTS $§ 282 \mathrm{cmt}$. e(5) (1965).

114 Id. $\S 500$. 
recklessness and a standard of gross negligence as follows: gross negligence constitutes a rural physician's conscious failure to conform his conduct to that of a reasonable physician with ordinary skill, knowledge, and expertise, after the rural physician was supplied with facts which would lead a reasonable physician to appreciate the existence of an unjustifiable risk that is moderately greater than a risk that would result in negligent conduct. Thus under this standard, a rural physician's conduct can fall below the conduct of a reasonably skillful, knowledgeable, and prudent physician generally without liability attaching. Moreover, even if a rural physician's performance falls below the national standard of care and his conduct creates a minimally greater risk than a risk usually resulting in negligence, no liability would attach because the minimally greater risk is not moderately greater.

Arguably, under a gross negligence approach, the quality of care provided in rural areas would most likely degrade to a certain extent. Some physicians might even take advantage of a relaxed standard of care for whatever reason. ${ }^{115}$ Other rural physicians might unintentionally and subconsciously perform less effectively than they are capable of performing due to the gross negligence standard. Of course, some patients, who would normally recover under a medical malpractice claim, would be barred from recovery due to the heightened burden of proving gross negligence.

Due to moral, utilitarian, and tort policy justifications supporting compensatory recovery by an injured party from a tortfeasor under traditional malpractice liability, some exceptions to the application of gross negligence in the rural medical malpractice context are appropriate. Where a patient dies or is severely and permanently injured or disabled by the alleged malpractice of a rural physician, the standard of gross negligence should not apply. In these two instances, it is quite clear that the purpose of increasing the number of physicians in rural areas to augment access to healthcare would be thwarted because rural individuals would be less likely to seek treatment given the increased

115 It is presumed here that physicians are aware of the law and make decisions in light of it. 
severity of potential injury and the absence of stringent legal constraints on rural physicians' conduct.

The promotion of greater accessibility to medical care in rural areas outweighs the costs to quality. Providing more individuals with access to care is fundamental. Temporary costs to quality must be tolerated in order to maximize longterm societal gain. Once inaccessibility is eradicated or under appropriate control, then it will be appropriate to slowly remove the restraints on quality which were originally necessary to augment accessibility. Thereafter, it will be advisable to focus more resources towards improving quality of medical service in rural areas.

\section{PART III}

\section{A. Existing Accessibility Programs}

The federal government has created programs to address the inaccessibility of medical care in rural areas. These include physician scholarship and loan repayment programs, rural health clinical programs, Medicare payment programs, a $\mathrm{J}-1$ visa waiver for physicians, and Federally Qualified Health Center funding. 116 The State of Indiana must take advantage of these programs in order to address the demand for physicians in rural areas. Without sustained reliance on these federal programs, state initiated alternatives will most likely lack adequate force in remedying the disparate allocation of medical resources. Some of these programs will be described below.

The Public Health and Services Act establishes funding for Federally Qualified Health Centers. ${ }^{117}$ Under the Act, qualified entities may receive grants to "plan and develop health centers which will serve medically underserved populations." ${ }^{118}$ Additionally, grants may be awarded to

116 Ind. State Dep't of Health, Health Professional Shortage Areas, IN.Gov, http://www.in.gov/isdh/23471.htm (last visited Oct. 14, 2013).

117 Health Res. \& Servs. Admin., U.S. Dep't of Health and Human Servs., About Health Centers: What is a Health Center?, HRSA.Gov, http://bphc.hrsa.gov/about/ (last visited Oct. 14, 2013).

11842 U.S.C. $\$ 254 b(c)(1)(A)(2012)$. 
health centers to "enable the centers to plan and develop a managed care network or plan . . ." and to "plan and develop practice management networks." 119 Importantly as well, grants are available to the health centers to aid in meeting operating costs. ${ }^{120}$ In order receive the grants above, the entity must be either public or non-profit private and provide primary care and additional services to a medically underserved population. ${ }^{21}$

Under the J-1 visa waiver program, the Indiana State Department of Health is permitted to submit recommendations to the Bureau of Citizenship and Immigration Service of the U.S. Department of Homeland Security for the approval of a waiver for recent foreign graduates of medicine. ${ }^{122}$ Without this waiver, fresh foreign graduates are required to return to their home countries for two years. ${ }^{123}$ The Indiana State Department of Health may submit approval recommendations for thirty foreign physicians per year. ${ }^{124}$ In order to qualify for approval of the waiver, foreign physicians must be willing to practice in a primary care health professional shortage or a medically underserved area or population and practice there for at least three years. ${ }^{125}$ This program is engineered to retain foreign physicians in order to fulfill the need for medical professionals.

Under the State Loan Repayment Program, the federal government provides funding to state governmental agencies to repay student loan obligations of primary care

\footnotetext{
119 Id. $\S 254 \mathrm{~b}(\mathrm{c})(1)(\mathrm{B})-(\mathrm{C})$.

120 Id. $\S 254 \mathrm{~b}(\mathrm{e})(1)(\mathrm{A})$.

121 Id. $\$ 254 \mathrm{~b}(\mathrm{a})(1)(\mathrm{A})-(\mathrm{B}),(\mathrm{c})(1)(\mathrm{A}),(\mathrm{e})(1)(\mathrm{A})$.

122 Ind. State Dep't of Health, Programs Using Shortage Designations: Indiana $J-1$ Visa Waiver Program Guidelines, IN.Gov, http://www.in.gov/isdh/files/IN_J-1Program_Guidlines_2012-13d(1).pdf (last visited Oct. 27,2013$)$.

123 Ind. State Dep't of Health, Programs Using Shortage Designations, IN.Gov, http://www.in.gov/isdh/24409.htm (last visited Oct. 27, 2013).

124 Id.

125 Ind. State Dep't of Health, supra note 122, at 1-2. There are additional requirements that the medical employer must meet. One such requirement makes approval of the waiver conditioned upon the medical employer being able to show that it has attempted to hire a U.S. Citizen for the position. Id. at 2 .
} 
physicians who agree to work in health professional shortage areas. ${ }^{126}$ However, for a state to take part in the program, it must promise to match each dollar of federal funding. ${ }^{127}$ Primary care physicians participating in the loan repayment program must agree to work for a public or non-profit entity that provides medical services in a health professional shortage area. ${ }^{128}$ Currently, Indiana has halted its involvement in the State Loan Repayment Program because it is unable to provide the necessary state funding. ${ }^{129}$

While Indiana funds community health centers, these centers are an inadequate means of addressing the disparity of access to healthcare. In Indiana, there exist forty-eight community health centers. Of the forty-eight community health centers, nineteen are classified as Federally Qualified Health Centers. ${ }^{130}$ The State of Indiana finances these community health centers through an established tobacco settlement fund. ${ }^{131}$

In order to receive funding as a community health center, the facility must provide primary care services for at least twenty hours per week. ${ }^{132}$ While this particular prerequisite to funding is not indicative of the actual amount of time spent providing primary care services, it is nonetheless illustrative of the potential inadequacy of the

126 Nat'l Health Serv. Corps, U.S. Dep't of Health and Human Servs., SLRP Grantees: State Loan Repayment Program, NHSC.HRSA.Gov, $\mathrm{http} / / /$ hhsc.hrsa.gov/currentmembers/stateloanrepaymentprogram/index.html (last visited Oct. 27, 2013).

127 Nat'l Health Serv. Corps, U.S. Dep't of Health and Human Servs., SLRP Funding Requirements: Cost-Sharing Requirement, NHSC.HRSA.Gov, $\mathrm{http} / / /$ nhsc.hrsa.gov/currentmembers/stateloanrepaymentprogram/funding/i ndex.html (last visited Oct. 27, 2013).

128 Nat'l Health Serv. Corps, U.S. Dep't of Health and Human Servs., SLRP Eligibility Requirements: Eligible Sites, NHSC.HRSA.Gov, http://nhsc.hrsa.gov/currentmembers/stateloanrepaymentprogram/eligibility /index.html (last visited Oct. 27, 2013).

129 Ind. State Dep't of Health, supra note 123.

130 AFFLIIATED SERV. PRoviders of IND., INC., IND. STATE DEP'T OF HEALTH, supra note 2, at 39.

131 Ind. State DeP'T of Healith, MaPPING INDIANa COMMUNITy Health CENTERS, Fiscal Year 20082 (2007).

132 Id. 
community health centers to broadly service a large percentage of the population which is medically underserved. Additionally, notwithstanding the existence of these community health centers, many rural areas remain medically underserved and still suffer a shortage of medical professionals. ${ }^{133}$

The Indiana Department of Health has partnered with Minnesota Department of Health and the Wisconsin Department of Health Services to fund promulgation of an assessment and plan to aid rural medical facilities in recruiting and retaining health professionals. ${ }^{134}$ These state departments charged the National Rural Health Resource Center ("Resource Center") and National Rural Recruitment and Retention Network ("Retention Network") to create the assessment and plan, and the Resource Center and the Retention Network released its product called The Midwest Retention Toolkit ("the Toolkit") in 2012.135 Specifically, the Toolkit is intended to provide medical facilities that are located in medically underserved areas insightful data and methods to retain physicians practicing in their facilities under the National Health Services Corps Loan Repayment Programs. ${ }^{136}$ The Toolkit contains sample strategies in the areas of physician orientation and assimilation, physician compensation, mentoring, workplace recognition, and workplace departure of which medical facilities may implement. ${ }^{137}$

All of the aforementioned federal and state programs are pertinent measures of focusing governmental resources on medical care inaccessibility in rural areas. Some of these measures take aim at geographic inaccessibility of medical care while others are designed to foster the medical practice of health professionals in rural areas. Some of these measures are more effective than others due to their very

133 Health Res. \& Servs. AdMIN., U.S. DeP'T OF HEAlth \& HumaN SERVS., supra note 22 , at 8.

134 The NaT'L RuRal Health Res. CTR. \& THE NAT'L RuRaL RECRUITMENT AND RETENTION NETWORK, MDWEST RETENTION TOOLKIT 2012 i, 1 (2012), available at http://www.in.gov/isdh/24409.htm.

135 Id.

136 Id. at 1.

137 Id. at $4-8,11-55$. 
nature. Direct measures, such as the Federally Qualified Health Centers, increase accessibility more than indirect measures such as the Toolkit mentoring strategies. However, not a single measure alone can bring about a sweeping change in the distribution of medical resources. Only all of the above mentioned measures combined and with the addition of some direct, human capital oriented, and financially vigorous legislative measures may begin to accelerate and widen the accessibility of medical care within rural Indiana.

\section{B. Critical Access Hospitals}

Critical access hospitals ("CAHs") are indispensable to the healthcare network in Indiana. These hospitals are located strategically in rural areas where other sources of medical care are scarce or wholly absent. The construction of new critical access hospitals is a great starting point to address the inaccessibility of medical care in Indiana.

Under the Social Security Act, any state may submit an application to establish a Medicare Rural Hospital Flexibility Program ("Flex Program"). ${ }^{138}$ In taking part in this Flex Program, a state must designate at least one medical facility as a critical access hospital. ${ }^{139}$ In order to receive a critical access designation, a medical facility must meet the following non-exhaustive criteria:

i. is a hospital that is located in a county (or equivalent unit of local government) in a rural area (as defined in section $1395 w w(d)(2)(D)$ of this title) or is treated as being located in a rural area pursuant to section $1395 w w(d)(8)(E)$ of this title, and that-

ii. is located more than a 35 -mile drive (or, in the case of mountainous terrain or in areas with only secondary roads available, a 15-mile 
drive) from a hospital, or another facility described in this subsection; or

iii. is certified before January 1,2006 , by the State as being a necessary provider of health care services to residents in the area; 140

The hospital must also provide twenty-four hour emergency care services. ${ }^{141}$ There are additional requirements that will not be mentioned here. ${ }^{142}$ States that have submitted an application to establish a Flex Program may receive grants from the federal government to assist in implementing the program and increasing medical care quality in critical access hospitals. ${ }^{143}$

Currently, there are thirty-five critical access hospitals operating in Indiana. ${ }^{144}$ These CAHs however suffer a shortage of health professionals. ${ }^{145}$ Specifically, it is estimated that on average each Indiana CAH has from one to seven full-time job openings per week. ${ }^{146} \mathrm{CAHs}$ also suffer from an inability to staff part-time positions. ${ }^{147}$ Moreover, filling these positions could not be completed in less than several months. ${ }^{148} \mathrm{In}$ order to increase the effectiveness of existing CAHs, state recruitment and retention measures of health professionals must be adopted.

\section{Geographic Accessibility: State-Owned and Operated} Critical Access Hospitals and Support for the Establishment of Acute Care and Primary Care Hospitals

In fiscal year 2009, Indiana received the least amount of funding (fiftieth) from the HRSA. ${ }^{149}$ In the same year,

$140 \quad$ Id. $\S 1395 \mathrm{i}-4(\mathrm{c})(2)(\mathrm{B})(\mathrm{i})(\mathrm{I})-(\mathrm{II})$.

$141 \quad$ Id. $\$ 1395 \mathrm{i}-4(\mathrm{c})(2)(\mathrm{B})(\mathrm{ii})$.

142 Id. $\S 1395 \mathrm{i}-4(\mathrm{c})(2)(\mathrm{B})(\mathrm{iii})-(\mathrm{v})$.

143 Id. $\S 1395 \mathrm{i}-4(\mathrm{~g})(1)(\mathrm{A})-(\mathrm{D})$.

144 AfFiliated Serv. Providers of IND., InC., IND. State DeP'T of HEALTH, supra note 2 , at 33.

145 See id. at 62.

146 Id.

147 See id.

148 Id. 
Indiana ranked forty-eighth in the amount of funding received from the Center for Disease Control.150 Moreover, the State of Indiana falls behind forty-six states in funding public health. ${ }^{151}$ The failure of the state government to acquire federal funding and to adequately provide state funding to strengthen the health of its residents is regrettable. Indiana must diligently strive to obtain federal benefits in order to comprehensively fortify the healthcare delivery system and support the health of its residents.

If Indiana decides to address the inaccessibility to medical care problem, then federal funding must be exploited as much as possible in order to limit the extent to which state monies are diverted from state programs in other areas. Due to the recent downturn in the economy, states' budgetary capacities have dwindled. Due to this drop in revenues, budget wars have ensued with each political party targeting different expenditure programs for cuts. A failure to rely on federal monies in combination with a continuing reliance on the expenditure of state monies to increase access to healthcare at the state level may exacerbate the targeting of important state or local expenditure programs outside the realm of healthcare. Of course, it may be argued that a potential exacerbation of budget cuts could be avoided by deferring reformation of healthcare to more prosperous times. However, this approach is untenable because the consequences of an unhealthy population are detrimental in the short term and in the long run. What is more, if Indiana continues to fall behind in acquiring federal funds then the state will shoulder a substantial amount of the costs in reforming the healthcare delivery system. A continued failure to acquire federal funding while implementing accessibility measures at the state level may force the state to unnecessarily increase taxes on Hoosiers. While some of the legislative measures proposed below will require an increase in taxation, the increase may be lessened through reliance on federal monies.

149 Id. at 14.

150 Id.

151 Id. 
While federal initiatives and financial support are needed to resolve the inaccessibility of medical care, the state government is in a better position to understand the shortcomings of the local healthcare system and the complexities therein involved. ${ }^{152}$ Despite the fact that the federal government has many resources at its disposal, the state government would most likely be better able to evaluate the current state of medical inaccessibility in rural Indiana. The state government's scope of evaluation is geographically smaller, whereas the federal government must evaluate the state of healthcare throughout the United States. This large federal scope of evaluation takes resources such as time and money away from Indiana. Additionally, channels of information sharing at the state level are more easily ascertainable and direct than those at the federal level. The sheer size of the federal government as compared to state governments may create the risks of misdelivery of information and the proliferation of misinformation. Valuable information about the nuances of healthcare system and the general state thereof in Indiana can be streamlined to the appropriate state agencies. This streamlining of information would allow the Indiana Legislature to efficiently expend resources toward the heart of the nuanced issue.

Additionally, the state government must live with the detrimental consequences of an ill-functioning system of healthcare. Deprivation of good health in Indiana most likely affects the local economy. Poor economies have the potential to undermine governments in several ways. Continued governmental inaction might maintain or even worsen the substandard performance capacity of rural economies resulting in a continued reliance on social welfare funds, the minimization of taxation sources, and an overall stagnation of progress.

It is imperative that the Indiana Legislature recognize its failure to adequately address the inaccessibility of healthcare in rural areas and seek to remedy the disparity

152 See Kristine Marietti Byrnes, Is There a Primary Care Doctor in the House? The Legislation Needed To Address a National Shortage, 25 RUTGERS L.J. 799, 834-35 (1994). 
through direct financial support. If left unresolved, the prevalent inaccessibility of healthcare in rural communities could continue to degrade the health of rural citizens and hamper those rural communities from progressing educationally and economically. In order to directly advance accessibility, the Indiana Legislature should establish some state-owned and operated critical access hospitals and partner with Indiana University Health or any willing private entity to establish new acute and primary care hospitals in counties where they are nonexistent or highly needed.

Under the Indiana Flex Program, a statutory transition of small rural hospitals into $\mathrm{CAHs}$ is one of four objectives. ${ }^{153}$ While this objective is a positive step toward acquiring more federal funding for Indiana's rural healthcare delivery system, it falls short of proactively and directly advancing accessibility in rural communities. Specifically, the rural hospitals that are intended for transition already exist. The transition would increase funding, but it would not dramatically expand accessibility. The construction of state-run critical access hospitals on the other hand would immediately expand accessibility in communities where no medical facility exists.

It is estimated that it would costs anywhere from 10.8 to 12.1 million dollars to construct a two or three story hospital in Washington, Indiana. ${ }^{154}$ Due to the exorbitant costs of constructing and operating hospitals, Indiana should plan to construct a minimal number of critical access hospitals in rural areas where they are most needed. Another option is to acquire existing buildings and convert them into hospitals. This would most likely be a less expensive route. Also, it might be possible for Indiana to receive federal funding to aid in meeting the costs of

153 AFFILIATEd SERV. PRoviders of IND., INC., IND. STATE DEP'T OF HEALTH, supra note 2, at 51.

154 RSMEANS: Construction Cost Estimates for Hospital (2-3 Story) in Washington, Indiana, REEDCONSTRUCTIONDATA.COM, http://www.reed constructiondata.com/rsmeans/models/hospital/indiana/washington/ (last visited Oct. 18, 2013). Washington, Indiana was used for the construction cost estimate because of its rural location. 
construction, acquisition, and operation of these critical access hospitals. ${ }^{155}$

The state-run facilities should be small rural hospitals, much like the other Indiana critical access hospitals. They would provide acute care and primary care medical services, including immeasurably important services such as obstetrics. The State of Indiana already operates six psychiatric health hospitals. ${ }^{156}$ This operation could act as a model for state-operated acute and primary care hospitals.

There are many advantages of state-run hospitals. The establishment of state-run hospitals is the most direct legislative means to facilitating better access to healthcare in rural communities. If strategically placed, the establishment of these state-run hospitals would immediately open the door to medical care access. This establishment would remove barriers to obtaining medical services. In particular, rural residents would no longer be required to drive counties away to see a physician, and also timely treatments could be obtained. Moreover, these small hospitals would obviously have a larger operating capacity than existing community health centers, and therefore they could provide more services to many more rural patients. Indiana might be able to eventually remove the medical underservice and the professional shortage area designations if it establishes state-operated hospitals and partners with IU Health or a private entity to further expand its operations.

Another advantage is that state-run facilities would not operate on the principal of maximizing profit, but rather their primary goal would be to provide as many health services as needed to the most people as possible. Also,

15542 U.S.C. $\S 1395 \mathrm{i}-4$ (g)(A)-(C) (2012) (whether or not grants may be awarded for construction costs is unclear and this determination revolves around the Secretary's interpretation of the statute); Id. $\S 254$ (b)(c)(1)(A) (authorizing the Secretary to award grants to public entities to aid in acquiring buildings and equipment in the establishment of health centers); Id. $\S 254(\mathrm{~b})(\mathrm{e})(1-2)$ (giving discretion to Secretary to award grants to health centers to meet operating costs).

156 Div. of Mental Health \& Addiction, Ind. Family \& Social Servs. Admin., Mental Health Services: State Psychiatric Hospitals, IN.Gov, http://www.in.gov/fssa/dmha/4325.htm (last visited Oct. 18th, 2013). 
state-run facilities could potentially lessen the burden on non-profit hospitals of providing patient care. Additionally, state-run facilities could potentially assume more of the uncompensated patient care expenses of which non-profit hospitals in Indiana shoulder the most. ${ }^{157}$ Lastly, the spending of funds for state-operated hospitals would be more transparent and easily traceable than subsidies given to private institutions.

Building some state-run hospitals would create jobs in rural areas and would also in turn foster a growth of support industries and businesses around these medical centers. At the start for example, the state would award construction contracts to companies to build the hospitals which would require those companies to hire laborers. This would immediately create ancillary jobs. Also, once these new hospitals began operation, they would immediately create demand for health goods. It is estimated that American hospitals spend 702 billion dollars on goods and services. ${ }^{158}$ These operating expenditures have created a 9.9 million job market outside of the hospital infrastructure. ${ }^{159}$

There are of course disadvantages of establishing staterun hospitals. The most obvious disadvantage of state-run hospitals is the potential for high and unbearable costs of construction, maintenance, and operation which taxpayers must bear. Building the hospitals would require the state to take bids on and pay out construction contracts of ten to twelve million dollars each. 160 Paying health care professionals to work in these facilities is not the only operational cost associated with establishing state-run hospitals. Additionally, the state would have to purchase expensive medical devices and supplies. The state would

157 DAVID M. WALKER, U.S. GOV'T ACCOUNTABILITY OFFICE, GAO-05743T, NONPROFIT, FOR-PROFIT, AND GOVERNMENT HOSPITALS: UNCOMPENSATED CARE AND OTHER COMMUNITY BENEFITS 11 (2005), available at http://www.gao.gov/new.items/d05743t.pdf.

158 AMERICAN HOSP. ASS'N, ECONOMIC CONTRIBUTION OF HOSPITALS OFTEN OVERLOOKED (2013), available at http://www.aha.org/content/13/ 13brief-econcontrib.pdf .

159 Id.

160 However the state might be able to obtain federal funding to assist in meeting these costs. 
also be required to staff administrative positions in order to properly operate the facilities. In general, most likely 44 percent of a state-run rural hospital's expenses would be attributable to labor costs. ${ }^{161}$ However, the severity of these costs can be mitigated by the adoption of a dualistic operating-model whereby the state government operates some hospitals and a private entity operates others.

Another potential disadvantage, and one which is oft cited whenever government provided health care is debated, is the claim that government will refuse expensive and important treatment for certain ailments in order to avoid costs. This assertion however unconvincingly presupposes an indifferent governmental predisposition toward the wellbeing of its citizens. This argument is also propounded in terms of demonizing labels, and it usually refers to government involvement in the provision of medical care as socialized medicine. However, it is not proposed here that the state government should assume the role of great arbiter of medical treatment or much less even seek to minimize the involvement of the private sector in the medical industry. All that is proposed here is that state government should provide an important service where the private sector refrains from doing so.

Even though there are many advantages of state-owned and operated critical access hospitals, it is necessary to contemplate supplementary or alternative measures which are financially more reasonable. Thus, a supplement or an alternative to state-owned and operated critical access hospitals is a state funded expansion of IU Health into rural areas. Under this model, the state government would bear part of the costs of constructing the hospitals. Conversely, IU Health would operate and maintain the hospitals. IU Health therefore would pay medical supply, labor, general operation, and maintenance costs yet it would avoid most of the acquisition or construction costs.

Another supplementary or alternative approach would be privatization of the expansion of hospitals into rural areas. Under this approach, the state government would

161 AFFiliated Serv. Providers of IND., INC., IND. STate DeP'T OF HEALTH, supra note 2, at 37 . 
operate a smaller number of rural hospitals, but it also would provide benefits to private healthcare companies who expand and establish healthcare facilities in rural areas. Particularly, under this model, in order to incentivize companies to establish small rural hospitals, the state government would create tax incentives. These tax incentives could take the form of qualified excepted income and significant tax credits. Of course, these incentives would only be applicable for a defined statutory period. This privatization approach, unlike the aforementioned approaches, significantly decreases the amount of out-going expenditures. However, it also decreases the amount of incoming tax revenue. Despite this, this hybrid approach is feasible, viable, and it has the potential to bring better access to medical care to rural areas.

\section{Medical Personnel Accessibility: The "Pay-to-Drive" and the "Rural Practice Benefits Program"}

The Indiana Legislature should enact a program which promotes and facilitates metropolitan and out-of- state physicians to travel to rural communities within Indiana to practice for limited duration on a regular basis. This hypothetical program will be referred to as the "Pay-toDrive" Program. This program would pay 40 percent of the traveling physician's compensation per day (of what the physician would have earned working at his principal hospital or facility) when working in a designated health professional shortage area or medically underserved area, and it would also pay traveling expenses. Rural hospitals wishing to participate would be required to pay at least 65 percent of the traveling physician's contractual compensation. In all, the traveling physician would earn 105 percent per day of his normal pay.

Under the program, the state would also provide tax benefits to the principal medical institutions where the traveling physician normally works. These tax benefits would constitute tax credits. These tax benefits conferrable to the traveling physician's principal hospital would act as incentive for metropolitan hospitals to leave room in 
physicians' contracts to allow them to participate in the "Pay-to-Drive" program. Specifically, these tax benefits, by decreasing tax liability, would be a form of compensation for the metropolitan hospitals for their temporary loss of human capital. Also, the program would cap the number of days available for qualifying metropolitan physicians to travel to rural areas. This restraint would exist to avoid high costs. Additionally, the program would specify the days that physicians practicing at the same principal hospital could participate in order to ensure the principal hospital's capacity to meet the needs of its patients.

Metropolitan physicians wishing to participate in the program would be required to apply to become a traveling physician. In order to qualify, the metropolitan physician would be required to show that he or she had not been assessed more than two malpractice judgments in the last ten years of practice. This condition of participation would ensure that quality care would be provided to rural patients.

After successful participation in the Pay-to-Drive program for three years, the traveling physician would be permitted to apply to the "Rural Practice Benefits Program." Successful participation in the Pay-to-Drive program would constitute no more than one malpractice judgment assessed against the physician in the last three years. Also, to gain acceptance into this program, the traveling physician would necessarily have to submit at least two letters of recommendation from two senior (defined as number of years in practice) rural physicians with whom the traveling physician has worked.

Upon acceptance into the Rural Practice Benefits Program, the physician would be placed in a medically underserved rural area or health professional shortage area to work, and the physician would receive at least 100 percent of his former contractual compensation for five years (to be paid wholly by the rural medical institution). Additionally, the physician would be allowed to exclude from his income the amount of his compensation on his state return for five years, which would result in tax free compensation. Moreover, the physician's principal 
residence would not be assessed a state real property tax for five years.

\section{E. Conclusion}

In implementing some of the judicial measures aforementioned, particularly the adoption of gross negligence, the quality of care may be lowered. However, the risk of minimal degradation in quality of care is outweighed by the expansion of accessibility of medical care in rural areas. Specifically, it is better for individuals to have access to at least some care rather than to have no access at all. Once the inaccessibility of medical care is no longer a devastating problem, more quality measures should then be implemented to bolster sound medical performance.

Some of the legislative measures proposed here, such as the establishment of some state-run critical access hospitals, would be monetarily burdensome on the state government. However, increasing access to healthcare in rural areas is not a cheap endeavor. The high costs of establishing more hospitals can be lowered through hybrid measures which shift costs to the private sector. However even then, the state government must incur losses in the form of lost revenues due to the provision of tax incentives. Due to the high costs of direct state legislative action in this area, existing programs must be heavily relied on. Also, new measures such as the ones proposed here should be adopted and implemented lightly and with caution. Only after a newly implemented measure is proven to produce outstanding access to healthcare in rural areas should more resources be expended to enlarge its effect.

In summary, only a combination of impactful and thoughtful judicial measures can effectively begin to remedy the disparity of accessibility of medical care in Indiana. More importantly, judicial solutions alone will probably only result in lackluster results. Thus, it is imperative to consolidate judicial remedies with legislative ones in order to provide a comprehensive counterbalance to the inaccessibility of medical care. 